\title{
A FORMA ESPACIAL NA LITERATURA MODERNA ${ }^{1}$
}

Joseph Frank ${ }^{2}$

Laocoonte de Lessing, notou certa vez André Gide, é um daqueles livros que é bom reiterar ou contradizer a cada trinta anos. Apesar desse excelente conselho, nenhuma dessas atitudes para com Laocoonte foi adotada pelos escritores modernos ${ }^{3}$.

A tentativa de Lessing de definir os limites da literatura e das artes plásticas tornou-se questão encerrada - a qual ocasionalmente é feita uma referência respeitosa, mas que não suscita mais influência fecundante ao pensamento estético. Podemos entender como isso se sucedeu no século XIX, com sua paixão pelo historicismo, mas não é de entendimento muito fácil no presente, em que tantos escritores dedicados aos problemas estéticos têm se ocupado das questões da forma. Para um historiador da literatura ou das artes plásticas, o esforço de Lessing em definir as leis inalteráveis desses veículos pode bem ter parecido quixotesco; mas críticos modernos, que já não se assustam com o fantasma do método histórico, começam a considerar novamente os problemas que ele tentou resolver.

As soluções dadas por Lessing a esses problemas parecem, à primeira vista, ter pouca relação com o pensamento estético moderno. Os argumentos

\footnotetext{
${ }^{1}$ Extraído de The foundations of modern literary judgement, Nova York, Hancourt, Brace and company (editores, Mark Schorer, Josephine Miles \& Gordon Mckenzie, da Universidade da Califórnia), 1948, pp. 379-92. Nota da Edição americana: Spatial form in modern literature apareceu na The Sewanee Review, edições de primavera, verão e outono de 1945. Joseph Frank (nascido em 1918) gentilmente revisou e condensou seu ensaio para a presente publicação, encontrando-se ora impresso em sua nova forma com sua permissão e com a permissão do editor de The Sewanee Review.

2 Tradução de Fábio Fonseca de Melo. Reprodução autorizada pelo tradutor.

${ }^{3}$ Irving Babbitt, 1910, escreveu O novo Laocoonte com a intenção de fazer à arte moderna o que Lessing fez à arte de seus dias. Em suma, a tese de Babbitt era a de que, assim como a confusão de gêneros à época de Lessing pôde ser atrelada a uma falsa teoria da imitação, também as aberrações artísticas de nosso tempo poderiam ser atreladas a uma falsa teoria da espontaneidade. $O$ argumento de Babbitt, contudo, não tem nenhuma relação com as teorias de Lessing. A discussão de Lessing na primeira metade do livro reforça, meramente, a analogia entre os propósitos de Lessing e os de Babbitt.
} 
do Laocoonte direcionavam-se contra a poesia pictórica de seu tempo, que desde há muito deixou de interessar a sensibilidade moderna; e muitas de suas conclusões acerca das artes plásticas originaram-se de uma arqueologia hoje antiquada, que, para piorar ainda mais as coisas, Lessing conheceu, principalmente, de segunda mão. Mas foi precisamente sua tentativa quixotesca de superar a história, para definir as leis inalteráveis da percepção estética, antes que para atacar ou defender qualquer escola em particular, que deu a seu trabalho o frescor perene a que aludiu André Gide. Uma vez que a validade de sua tese central não depende de sua relação com os movimentos literários de seu tempo, nem da extensão de sua experiência direta com as obras de arte da Antiguidade, ela pode ser tomada à parte dessas circunstâncias e utilizada na análise de desenvolvimentos posteriores.

No Laocoonte, Lessing funde duas correntes de pensamento que eram de grande importância na história cultural de seu tempo. As pesquisas arqueológicas de Winckelmann, seu contemporâneo, estimularam um interesse apaixonado pela cultura grega entre os alemães. Lessing voltou a Homero, a Aristóteles e aos trágicos gregos, usando seu conhecimento direto para atacar as teorias críticas distorcidas, supostamente baseadas na autoridade clássica, que haviam se infiltrado na França através de comentadores italianos e só posteriormente empossadas na Alemanha. Ao mesmo tempo, como aponta Wilhelm Dilthey em seu famoso ensaio sobre Lessing, Locke e a escola empírica de filosofia inglesa haviam dado um novo impulso à especulação estética. Locke tentara resolver o problema do conhecimento, partindo idéias complexas em elementos simples de sensação, para, em seguida, examinar as operações da mente e verificar como essas sensações eram combinadas para formar idéias. Esse método foi rapidamente adotado pelos estetas, que, em vez de deitar regras para a beleza, começaram a analisar a percepção estética. Escritores como Shaftesbury, Hogarth, Hutcheson e Burke, para citar alguns poucos, interessaram-se pelo caráter e pela combinação de impressões precisos que deram prazer estético à sensibilidade. Mendelssonhn, amigo e 
aliado crítico de Lessing, popularizou esse método de tratar os problemas estéticos na Alemanha; o próprio Lessing era um estudante íntimo dessas obras e de muitas outras com o mesmo espírito geral. Laocoonte, por conseguinte, encontra-se na continência dessas correntes intelectuais: Lessing analisa as leis da percepção estética, mostra como elas prescrevem limitações necessárias à literatura e às artes plásticas e, então, demonstra como os escritores e pintores gregos, especialmente Homero, criaram obras-primas obedecendo a essas leis.

Seu argumento parte da simples observação de que a literatura e as artes plásticas, trabalhando através de veículos sensoriais diferentes, devem, portanto, diferir nas leis fundamentais que governam sua criação. "Se é verdade", escreveu Lessing, "que a pintura e a poesia, em suas imitações, fazem uso de meios ou símbolos inteiramente diferentes a primeira, a saber, de forma e cor no espaço, e a segunda, de sons articulados no tempo - , se esses símbolos requerem, indissoluvelmente, uma relação condizente com a coisa simbolizada, então está claro que os símbolos arranjados em justaposição podem expressar somente matérias cujas totalidades e partes sejam, elas mesmas, consecutivas". Lessing, obviamente, não inaugurou essa distinção, que vem sendo traçada desde as distâncias da Antiguidade clássica. Sua contribuição foi ter retirado tal distinção de um discernimento isolado e a alçado a princípio crítico universal, levando, dessa forma, à sua conclusão lógica os esforços dos críticos clássicos franceses em definir as leis imutáveis da arte conforme estabelecidas pela raison.

A forma nas artes plásticas, de acordo com Lessing, é necessariamente espacial, pois o aspecto visível dos objetos é melhor apresentado pela justaposição em um instante do tempo. A literatura, por outro lado, faz uso da linguagem, composta de uma sucessão de palavras que prosseguem através do tempo; e daí segue que a forma literária, para harmonizar com a qualidade essencial de seu veículo, deve se basear primariamente em alguma forma de seqüência narrativa. Lessing usou este argumento para atacar dois gêneros 
artísticos altamente populares em seus dias: a poesia pictórica e a pintura alegórica. A poesia pictórica tentava pintar com palavras, e a pintura alegórica contar uma história em imagens visíveis; ambas estavam fadadas ao fracasso, porque seus objetivos contradiziam as propriedades fundamentais de seus veículos. Não importava quão acurada e vívida uma descrição verbal pudesse ser, argumentava Lessing, ela não poderia dar a impressão unificada de um objeto visível; não importava quão habilmente as figuras fossem escolhidas e arranjadas, uma pintura ou peça de escultura não teria sucesso em narrar os diversos estágios de uma ação.

Lessing desenvolve seu argumento tentando provar que os gregos, com um infalível senso de propriedade estética, respeitavam os limites impostos aos diferentes veículos artísticos pela condição da percepção humana. A importância da distinção de Lessing, contudo, não depende dessas ramificações de seu argumento, nem mesmo de seus julgamentos específicos deste ou aquele escritor ou artista. Diversos críticos se engalfinharam com um ou outro desses julgamentos, achando que, assim fazendo, estariam de alguma forma minando a posição de Lessing; mas tal crença se baseia em uma má compreensão da importância do Laocoonte na história da teoria estética. Os discernimentos de Lessing podem ser usados unicamente como instrumentos de análise, sem avançar em julgamento de valor de obras individuais, considerando quão proximamente elas aderem às normas por ele estabelecidas; e, a menos que isso seja feito, para dizer a verdade, o real significado do Laocoonte não pode ser compreendido. Pois o que Lessing nos ofereceu não foi um novo conjunto de opiniões, mas uma nova concepção de forma estética.

A concepção de forma estética herdada da Renascença pelo século XVIII era puramente externa. Presumia-se que a literatura clássica - ou o que conhecemos dela - tivesse alcançado a perfeição, e tudo o que os escritores subseqüentes podiam fazer não ia muito além de imitar seu exemplo. Uma horda de comentadores e críticos deduziu certas regras das obras-primas 
clássicas - regras como as unidades aristotélicas, das quais Aristóteles jamais ouvira falar - e os escritores modernos foram advertidos a obedecer essas regras se desejassem agradar a um público cultivado. Gradualmente, essas regras se enrijeceram num molde externo no qual o material de uma obra literária devia ser vertido: a forma de uma obra não passava de um arranjo técnico ditado pelas regras. Tal noção mecânica de forma estética, todavia, levou a sérias perversões do gosto - Shakespeare foi considerado um bárbaro mesmo por escritores tão sofisticados quanto Voltaire, e Pope achou necessário usá-la na tradução de Homero para fazer um bom negócio editorial. O ponto de vista de Lessing, rompendo agudamente com essa concepção externa de forma, demarca a via para a especulação estética seguir no futuro.

Para Lessing, como vimos, a forma estética não é um arranjo externo provido por um conjunto de regras tradicionais: é a relação entre a natureza sensorial do veículo artístico e as condições da percepção humana. Assim como o homem natural do século XVIII não tinha afã pelas formas políticas tradicionais, mas dedicava-se a criá-las de acordo com sua própria natureza, também a arte devia criar suas próprias formas a partir de si mesma, em lugar de aceitá-las sem originalidade da prática do passado. A crítica não tinha que prescrever regras para a arte, mas explorar as leis necessárias pelas quais a arte governa a si mesma. A forma estética não devia mais ser confundida com meras externações da técnica - não era uma camisa-de-força dentro da qual o artista, a contragosto, tinha que forçar suas idéias criativas, mas sim emanava espontaneamente da organização da obra de arte como ela se apresentava à percepção. Tempo e espaço eram os dois extremos a definir os limites da literatura e das artes plásticas em sua relação com a percepção sensorial: e é possível, seguindo o exemplo de Lessing, traçar a evolução das formas artísticas por meio de suas oscilações entre esses dois pólos ${ }^{4}$.

\footnotetext{
4 A crítica de arte alemã, nestas últimas décadas, vem experimentando um verdadeiro renascimento ao longo das linhas demarcadas por Lessing. Seguindo a direção de Aois Riegl, o predecessor imediato daqueles escritores que, mais tarde, se ocupariam em traçar a história
} 
O propósito do presente ensaio é aplicar o método de Lessing à literatura moderna - para traçar a evolução da forma na poesia moderna e, mais particularmente, no romance moderno. As primeiras duas seções tentarão mostrar que a literatura moderna, exemplificada por escritores como T. S. Eliot, Ezra Pound, Marcel Proust e James Joyce, está se movendo na direção da forma espacial. Isso significa que cabe ao leitor apreender suas obras espacialmente, em um momento do tempo, antes que em uma seqüência. Até onde concerne ao romance, essa tendência alcança seu apogeu no notável livro de Djuna Barnes, O Bosque da Noite, que nunca recebeu a atenção crítica que merece ${ }^{5}$. Finalmente, uma vez que as mudanças na forma estética sempre envolvem mudanças maiores na sensibilidade de um período cultural em particular, será feito um esforço de delinear as atitudes espirituais que levaram à predominância da forma espacial.

A poesia anglo-americana moderna recebeu seu ímpeto inicial do movimento imagista dos anos diretamente precedentes e consecutivos à Primeira Guerra Mundial. O Imagismo foi importante não devido a alguma poesia eletiva escrita por poetas imagistas - ninguém sabe bem ao certo o que era um poeta imagista -, mas, antes, porque abriu o caminho para

da forma nas artes plásticas, os acadêmicos alemães traçaram as cambiantes apreensões do espaço que obser4varam na raiz das mudanças na forma estética. O Próximo passo foi conectar a mudança na apreensão do espaço com mudanças mais amplas na história da cultura. Finalmente, a investigação foi ampliada para incluir não apenas as artes plásticas, mas também a literatura e a música - introduzindo, assim, a categoria do tempo - e mesmo as concepções variáveis de espaço e tempo do pensamento filosófico como desenvolvimento paralelo às mudanças nas formas artísticas. A tentativa mais abrangente de tamanha síntese foi feita por Dagobert Frey em seu brilhante e sugestivo livro Gotik um Renaissance, publicado em 1929. Uma breve e excelente exposição desse movimento encontra-se em Die Philosophie der Kunstgeschichte in der Gegenwart, de Walter Passarge. Nesse ponto, devemos mencionar ainda Structure of the novel, de Edwin Muir, a única obra em inglês, até onde sabe o presente autor, que tenta discutir a forma na literatura em termos de espaço e tempo.

${ }^{5}$ No formato em que foi originalmente publicado, este ensaio continha uma análise detalhada de $\mathrm{O}$ bosque da noite (Nightwood), eliminado na presente versão. Os leitores interessados devem consultar a The Sewanee Review, edição de verão de 1945. 
desenvolvimentos posteriores, devido a seu honesto rompimento com a verbiagem sentimental vitoriana. Os escritos críticos de Ezra Pound, o teórico liderante do Imagismo, constituem uma assombrosa farragem de aguçadas percepções estéticas jogadas no meio de uma série de observações travessas pueris, cujo principal propósito, poderia parecer, é épater le bourgeois - chocar os engomadinhos. Mas a definição de imagem de Pound, talvez a mais aguçada de suas percepções, é de importância fundamental para qualquer discussão da forma literária moderna. "Uma imagem", escreveu Pound, "é aquilo que apresenta um complexo intelectual e emocional em um instante do tempo". As implicações dessa definição devem ser notadas - uma imagem é definida não como uma reprodução pictórica, mas como unificação de idéias e emoções díspares em um complexo apresentado espacialmente em um instante do tempo. Tal complexo não deve proceder discursivamente, segundo as leis da linguagem, mas deve, antes, fisgar a sensibilidade do leitor com um impacto instantâneo. Pound salienta esse aspecto, acrescentando, em uma passagem posterior, que somente a apresentação instantânea de tais complexos dá "aquela sensação de liberação repentina; aquela sensação de libertação dos limites do tempo e do espaço; aquela sensação de crescimento repentino que experimentamos na presença das maiores obras de arte".

Desde o princípio, portanto, a poesia moderna defendeu um método poético em direta contradição com o modo pelo qual, de acordo com Lessing, a linguagem tinha que ser percebida. Comparando a definição de imagem de Pound com a famosa descrição da psicologia do processo poético de Eliot, podemos ver claramente quão profundamente essa concepção influenciou nossa idéia moderna da natureza da poesia. Para Eliot, a qualidade distintiva de uma sensibilidade poética é sua capacidade de formar novas totalidades, de fundir aparentemente experiências díspares em uma unidade orgânica. $O$ homem ordinário, escreve Eliot, "se apaixona, ou lê Spinoza, e essas duas experiências não têm nenhuma relação entre si, ou com o barulho da máquina de escrever ou com o cheiro de comida cozinhando; na mente do poeta, essas 
experiências estão sempre formando novas totalidades". Pound, para se assegurar, tentou definir a imagem em termos de seus atributos estéticos, ao passo que Eliot, nessa passagem, está descrevendo suas origens psicológicas; mas o resultado em um poema era provavelmente muito parecido.

Essa visão da natureza da poesia imediatamente fez brotar inúmeros problemas. Como poderia ser incluída mais de uma imagem em um poema? Se o valor essencial de uma imagem era sua capacidade de apresentar um complexo intelectual e emocional simultaneamente, associar imagens claramente destruiria grande parte de sua eficácia. Ou era o poema ele mesmo uma vasta imagem, cujos componentes individuais deviam ser apreendidos como uma unidade? Mas, nesse caso, seria necessário superar a consecutividade inerente à linguagem, frustrando a expectativa normal de uma seqüência do leitor e forçando-o a perceber os elementos do poema como justapostos no espaço, em lugar de desdobrando-se no tempo.

Foi isso, precisamente, que Eliot e Pound tentaram em suas maiores obras. Ambos os poetas, em suas primeiras obras, ainda retinham alguns elementos da estrutura convencional. Seus poemas eram apreciados como ousados e revolucionários essencialmente por questões técnicas, como o afrouxamento do padrão métrico e a manipulação de assuntos ordinários que não eram considerados poéticos. Talvez isso seja menos verdade para Eliot que para Pound, especialmente o Eliot das obras iniciais mais complexas, como "Prufrock", "Gerontion" e "Retrato de uma Dama"; mas mesmo nelas, embora as seções dos poemas não sejam governadas por lógica sintática, o esqueleto de uma estrutura narrativa implicada está sempre presente. O leitor de "Prufrock" é arrebatado por um movimento narrativo logo nas primeiras linhas: "Vamos então, tu e eu / Quando a tarde...". E o leitor, acompanhando Prufrock, finalmente chega a seu mútuo destino: "As mulheres na sala vêm e vão caminhando / De Miguel Ângelo falando". Neste ponto, o poema inicia uma série de fragmentos mais ou menos isolados, cada um expondo algum aspecto do dilema emocional de Prufrock; mas os fragmentos estão agora localizados e 
focalizados em um conjunto específico de circunstâncias: o leitor pode organizá-los por referência à situação implicada. O mesmo método é empregado em "Retrato de uma Dama", ao passo que em "Gerontion" é dito especificamente ao leitor que ele está lendo "idéias de mente árida em árida estação" - a corrente de consciência de um "homem velho em mês seco, ouvindo a leitura que um jovem me faz, e a esperar pela chuva". Em ambos os casos, há uma armação perceptível em torno da qual as passagens aparentemente desconexas do poema podem ser organizadas. Esta foi uma das razões por que "Mauberly", de Pound, e as primeiras obras de Eliot foram vistas não como precursoras de uma nova forma poética, mas como vers de société contemporâneos - espirituosos, desiludidos, com um certo charme frágil, mas aos quais faltava aquela "alta seriedade" que Matthew Arnold havia selecionado como pedra de toque da excelência poética. Esses poemas foram considerados inusuais principalmente porque os vers de société haviam há muito saído de moda; havia um pouco de dificuldade em aceitá-los como uma abertura ao entretenimento, ao grande estilo do século XIX. Nos "Cantos" e em "A Terra Devastada", todavia, devia estar claro que uma transformação radical estava tendo lugar na estrutura estética: mas essa transformação foi tratada apenas perifericamente pelos críticos modernos. R. P. Blackmur chega mais perto do problema central ao analisar o que ele chama de método "anedótico" de Pound. A forma especial dos "Cantos", explica Blackmur, "é aquela da anedota iniciada em um lugar, continuada em um ou mais espaços diferentes e concluída, se absolutamente concluída, em ainda outro lugar. Essa desconexão deliberada, essa arte de algo continuamente aludindo a si mesmo, continuamente separando-se em retalhos menores, é o método pelo qual os 'Cantos' os amarra juntos. Tão logo a mente do leitor é concertada com o material do poema, o Sr. Pound deliberadamente a desconcerta, seja por introduzir um material novo e desconjunto, seja por reverter a um material anterior e, aparentemente, igualmente desconjunto". As observações de Blackmur se aplicam igualmente bem a "A Terra Devastada", em que a 


\begin{tabular}{|l|l|l|l|l|l|l|}
\hline InterteXto & Uberaba & UFTM & $\begin{array}{l}\text { v. } 1 \\
\text { n. } 2\end{array}$ & p. 167-198 & 2008 - jul. / dez. & ISSN 1981-0601 \\
\hline
\end{tabular}

seqüência sintática é abandonada por uma estrutura dependendo da percepção das relações entre grupos de palavras desconexos. Para serem bem compreendidos, esses grupos de palavras devem estar justapostos uns aos outros e serem percebidos simultaneamente; somente quando isso se dá é que podem ser adequadamente entendidos; pois embora eles sigam um ao outro no tempo, seu significado não depende dessa relação temporal. A dificuldade desses poemas, os quais nenhuma quantidade de exegese textual consegue vencer inteiramente, é o conflito interno entre a lógica temporal da linguagem e a lógica espacial implícita na concepção moderna da natureza da poesia.

A forma estética na poesia moderna, portanto, se baseia em uma lógica espacial que demanda uma completa reorientação da atitude do leitor frente à linguagem. Uma vez que a referência primária de qualquer grupo de palavras é algo interno ao próprio poema, a linguagem na poesia moderna é realmente reflexiva: a relação de significação é completada somente pela percepção simultânea no espaço dos grupos de palavras que, quando lidos consecutivamente no tempo, não têm relação compreensível entre si. Em lugar da referência instintiva e imediata das palavras e grupos de palavras aos objetos e eventos que simbolizam, e a construção do significado a partir da seqüência dessas referências, a poesia moderna pede a seus leitores que suspendam o processo de referência individual temporariamente, até que todo o padrão de referências internas possa ser apreendido como uma unidade, essa explicação, obviamente, é a afirmação extrema de uma condição ideal, antes que de um estado de coisas realmente existente: mas a concepção de forma poética que corre por Mallarmé a Pound e Eliot, e que deixou seus traços em toda uma geração de poetas modernos, pode ser formulada apenas em termos do princípio da referência reflexiva. E esse princípio é a ligação que conecta o desenvolvimento estético da poesia moderna a experimentos similares no romance moderno. 
Para um estudo da forma poética no romance moderno, a famosa cena do comício da feira de exposições em Madame Bovary é um ponto de partida conveniente. Essa cena foi louvada justamente por sua caricatura mordaz da pomposidade burguesa, seu retrato - inusualmente simpático para Flaubert do velho criado aturdido, e sua paródia da retórica pseudo-romântica pela qual Rodolfo corteja a sentimental Emma. No presente, é suficiente notar o método pelo qual Flaubert manipula a cena um método que poderíamos muito bem chamar de cinematográfico, já que essa analogia vem imediatamente à mente. Da maneira como Flaubert estabelece a cena, há ação acontecendo simultaneamente em três níveis, e a posição física de cada nível é um bom indicador de sua significância espiritual. No plano mais baixo, há a maré esbarrante da turba na rua, misturando-se ao gado em exposição; ligeiramente acima da rua, sobre uma plataforma, encontram-se os oradores oficiais, bombasticamente desfiando lugares-comuns para as multidões atentas: e no nível mais alto, observando o espetáculo de uma janela, Rodolfo e Emma assistem aos prosseguimentos e levam sua conversa amorosa em frases tão empoladas quanto aquelas que regalam a massa. Albert Thibaudet comparou essa cena à peça de mistério medieval em que diversas ações relacionadas ocorrem simultaneamente em níveis diferentes do palco; mas essa comparação aguda se refere à intenção de Flaubert, mais que a seu método. "Tudo devia soar simultaneamente", escreveu Flaubert mais tarde, comentando essa cena; "devia-se ouvir o berro do gado, os sussurros dos amantes e a retórica das autoridades, tudo ao mesmo tempo".

Mas como a linguagem procede no tempo, é impossível abordar essa simultaneidade de percepção, exceto pelo rompimento da seqüência temporal. $E$ é exatamente isso o que faz Flaubert: ele dissolve a seqüência, indo e vindo em cortes entre os diversos níveis de ação em um crescendo que vai lentamente acelerando até que - no clímax da cena - as frases 


\begin{tabular}{|l|l|l|l|l|l|l|}
\hline InterteXto & Uberaba & UFTM & $\begin{array}{l}\text { v. } 1 \\
\text { n. } 2\end{array}$ & p. 167-198 & 2008 - jul. / dez. & ISSN 1981-0601 \\
\hline
\end{tabular}

chateaubriendescas de Rodolfo são lidas quase no mesmo instante que os nomes dos ganhadores dos prêmios de melhor cultura de porcos. Flaubert tem o cuidado de sublinhar essa similaridade satírica pela descrição, bem como pela justaposição, como se temesse que as relações reflexivas das duas ações não fossem captadas: "Do magnetismo, Rodolphe passou, pouco a pouco, às afinidades e, enquanto o senhor presidente citava Cincinato empunhando seu arado, Diocleciano plantando suas couves e os imperadores da China inaugurando o ano para as sementeiras, o rapaz explicava à jovem senhora que as atrações irresistíveis tinham sua causa numa existência anterior".

Esta cena ilustra, em pequena escala, o que queremos dizer pela espacialização da forma em um romance. Pela duração da cena, pelo menos, o fluxo de tempo da narrativa é detido; a atenção é posta na interação das relações dentro da área de tempo delimitada. Essas relações são justapostas de forma independente do progresso da narrativa; a total significância da cena é dada somente pelas relações reflexivas entre as unidades de significação. $\mathrm{Na}$ cena de Flaubert, entretanto, a unidade de significação não é, como na poesia moderna, um grupo de palavras ou um fragmento ou uma anedota; é a totalidade de cada nível de ação tomada em conjunto: a unidade é tão grande que a cena pode ser lida com a ilusão de completo entendimento, ainda que com uma total inconsciência da "dialética do lugar-comum" (Thibaudet) entrelaçando todos os níveis e, finalmente, ligando-os conjuntamente em ironia devastadora. Em outras palavras, a luta pela forma espacial em Pound e Eliot resultou no desaparecimento da seqüência coerente após algumas poucas linhas; mas o romance, com sua maior unidade de significação, consegue preservar a seqüência coerente dentro da unidade de significação e quebrar apenas o fluxo de tempo da narrativa. (Devido a essa diferença, os leitores de poesia moderna são praticamente forçados a ler reflexivamente para apanhar algum sentido literal, enquanto os leitores de um romance como $O$ Bosque da Noite, por exemplo, são levados a esperar uma seqüência narrativa dentro da unidade de significação.) Mas isso não afeta o paralelo entre a forma estética 
na poesia moderna e a forma da cena de Flaubert: ambas só podem ser bem compreendidas quando suas unidades de significação são apreendidas reflexivamente, em um instante do tempo.

A cena de Flaubert, embora interessante nela mesma, é de menor importância para seu romance como um todo, e é habilidosamente reincorporada na estrutura narrativa principal após cumprir sua função satírica. O método de Flaubert, contudo, foi emprestado por James Joyce e aplicado em escala gigantesca na composição de Ulisses. Joyce compôs seu romance com um número infinito de referências e referências cruzadas que se relacionam independentemente da seqüência de tempo da narrativa; essas referências devem ser conectadas pelo leitor e visualizadas como um todo para que o livro possa caber em algum padrão significativo. Em última análise, se quisermos acreditar em Stuart Gilbert, esses sistemas de referência formam uma figura completa de praticamente tudo sob o sol - dos estágios da vida do homem e dos órgãos do corpo humano às cores do espectro; mas essas estruturas são muito mais importantes para Joyce, como observou Harry Levin, do que jamais poderiam ser para o leitor. Os estudiosos de Joyce, fascinados por sua erudição, vêm normalmente se dedicando à exegese, negligenciando, infelizmente, o problema da forma com que estamos lidando.

A intenção mais óbvia de Joyce em Ulisses é dar ao leitor uma figura de Dublin vista como um todo para recriar as vistas e sons, as pessoas e os lugares de um dia típico em Dublin, tanto quanto Flaubert recriou sua feira de exposições provinciana. Como Flaubert, Joyce queria que sua representação tivesse o mesmo impacto unificado, a mesma sensação de atividade simultânea ocorrendo em diferentes lugares. Joyce, para dizer a verdade, faz uso, com freqüência, do mesmo método de Flaubert indo e vindo em cortes entre diferentes ações que ocorrem ao mesmo tempo - e, normalmente, o faz para obter o mesmo efeito irônico. Mas Joyce tinha o problema de criar essa impressão de simultaneidade para a vida de uma cidade prolífica inteira, e de mantê-la — ou, antes, de fortalecê-la - por centenas de páginas que devem ser 
lidas em seqüência. Para resolver esse problema, Joyce foi forçado a ir muito além do que fora Flaubert: enquanto Flaubert manteve uma linha narrativa com cortes claros, exceto pela cena da feira de exposições, Joyce quebra sua narrativa e transforma a própria estrutura de seu romance em um instrumento de sua intenção estética.

Joyce, sabemos nós, concebeu Ulisses, como um épico moderno. No épico, como nos diz Stephen Dedalus em Retrato do artista quando jovem, "a personalidade do artista, no começo um grito, ou uma cadência e depois uma fluida e radiante narrativa, acaba finalmente se clarificando fora da existência, despersonalizando-se, por assim dizer [ ... ] o artista, como o Deus da criação, permanece dentro, ou junto, atrás ou acima da sua obra, invisível, clarificado, fora da existência, indiferente, raspando as unhas dos seus dedos". O épico, para Joyce, é, destarte, sinônimo do completo auto-apagamento do autor; e com seu usual rigor intransigente. Joyce leva essa implicação mais longe do que alguém jamais ousara antes. Ele assume, em primeiro lugar, que seus leitores são dublinenses, intimamente familiarizados com a vida em Dublin e a história pessoal de seus personagens. Isso the permite abster-se de dar qualquer informação diretiva sobre seus personagens, pois tal informação delataria imediatamente a presença de um autor onisciente. O que Joyce faz, em vez disso, é apresentar os elementos de sua narrativa - as relações entre Stephen e sua família, entre Bloom e sua esposa, entre Stephen e Bloom e a família de Dedalus - em fragmentos, à medida que são lançados sem explicação no curso da conversação casual, ou à medida que eles vão sendo embutidos nos diversos estratos de referência simbólica; e o mesmo é verdade também para todas as alusões à vida e à história de Dublin e aos eventos externos das vinte e quatro horas durante as quais o romance tem lugar. Em outras palavras, todo o plano de fundo factual tão convenientemente resumido para o leitor em um romance ordinário deve ser reconstruído a partir de fragmentos, por vezes distantes centenas de páginas, dispersados pelo livro. Como resultado, o leitor é forçado a ler Ulisses exatamente da mesma maneira 
que lê poesia moderna - montando os fragmentos continuamente e guardando as alusões na mente até que, por referência reflexiva, ele possa ligá-las a seus complementos.

Joyce tencionava, dessa forma, criar na mente do leitor uma sensação de Dublin como uma totalidade, inclusive todas as relações dos personagens entre si e todos os eventos que adentram suas consciências. À medida que o leitor progride no romance, conectando as alusões e referências espacialmente, tomando gradual consciência do padrão de relacionamentos, essa sensação devia ser imperceptivelmente adquirida; e, na conclusão do romance, poder-se-ia quase dizer, Joyce literalmente queria que o leitor se tornasse um dublinense. Pois é isso o que demanda Joyce: que o leitor tenha à mão o mesmo conhecimento instintivo da vida em Dublin, a mesma sensação de Dublin como um enorme organismo circundante, que o dublinense possui de berço por direito. Tal conhecimento, em qualquer momento do tempo, Ihe dá um conhecimento do passado e do presente de Dublin como um todo: e é só por esse conhecimento que o leitor, como os personagens, consegue colocar todas as referências em seus contextos apropriados. Isto, deve-se imaginar, praticamente equivale a dizer que Joyce não pode ser lido pode apenas ser relido. Um conhecimento do todo é essencial para a compreensão de qualquer parte: porém, a menos que se seja um dublinense, tal conhecimento só pode ser obtido depois da leitura do livro inteiro, estando todas as referências ajustadas em seus locais apropriados e apanhadas como uma unidade, embora os fardos confiados ao leitor por esse método de composição possam parecer insuperáveis, o fato ainda é que Joyce, em sua inacreditável fragmentação laboriosa da estrutura narrativa, procedeu assumindo que uma apreensão espacial unificada de sua obra, em última análise, poderia ser possível.

De uma maneira muito mais sutil que em Flaubert e Joyce, o mesmo princípio de composição está presente em Marcel Proust, uma vez que o próprio Proust nos diz que, antes de mais nada, seu romance terá impresso em 
si "uma forma que, normalmente, permanece invisível, a forma do Tempo", pode parecer estranho falar de Proust em conexão com a forma espacial. Quase sem exceção, ele tem sido considerado o romancista do tempo par excellence, o intérprete literário daquele "tempo real" bergsoniano que, quando intuído pela sensibilidade, nos põe em contato com a realidade última. Parar nesse ponto, entretanto, é perder o que o próprio Proust considerava a mais profunda significância de sua obra. Obsessivo pela inelutabilidade do tempo, Proust era visitado sem sobreaviso por certas experiências místicas que ele descreve em detalhe em $O$ tempo reencontrado, o último volume de sua obra de vários volumes. Essas experiências, proporcionando-lhe uma técnica para transcender o tempo, pareciam libertá-lo da dominação do tempo; e, escrevendo um romance, no qual ele traduziria as qualidades extratemporais dessas experiências no nível da forma estética, ele esperava revelar sua natureza ao mundo. Pois, como verdadeiro artista, ele não desejava apenas explicá-las conceitualmente - ele queria que o mundo sentisse o impacto emocional exato que ele próprio sentira.

Para definir como isso se dá, é necessário primeiro compreender claramente a natureza precisa da revelação proustiana. Cada experiência dessas, conta-nos Proust, é marcada por um sentimento de que "a essência permanente das coisas, normalmente encobertas, é libertada, e nosso verdadeiro eu, que parecera longamente morto, mas não estava morto de outras formas, desperta, respira vida nova à medida que recebe o alimento celestial que the é trazido". Esse alimento celestial consiste em algum som, ou odor, ou outro estímulo sensório, "sentido de maneira nova, simultaneamente no presente e no passado". Mas porque esses momentos deveriam parecer tão assoberbantemente valiosos para Proust chamá-los celestiais? Porque, observa Proust, a imaginação só consegue operar no passado; ao material apresentado à imaginação falta, portanto, qualquer imediação sensorial. Mas, em certos momentos, as sensações físicas do passado retornavam transbordantes para fundir-se com o presente; e nesses momentos, acreditava 


\begin{tabular}{|l|l|l|l|l|l|l|}
\hline InterteXto & Uberaba & UFTM & $\begin{array}{l}\text { v. } 1 \\
\text { n. } 2\end{array}$ & p. 167-198 & 2008 - jul. / dez. & ISSN 1981-0601 \\
\hline
\end{tabular}

Proust, ele apanhava uma realidade "real sem ser do momento presente, ideal mas não abstrata". Somente nesses momentos ele atingia sua ambição mais fundamental "apossar-se, isolar-se, imobilizar-se pela duração de um lampejo luminoso", o que, de outro modo, ele não poderia apreender, "a saber: um fragmento de tempo em seu estado puro". Para uma pessoa que experimenta esse momento, acrescenta Proust, a palavra "morte" deixa de ter significado. "Situada fora do escopo do tempo, o que ela poderia temer do futuro?"

A significância dessa experiência, embora obscuramente insinuada por todo o livro, é explicitada apenas nas páginas conclusivas que descrevem a aparência final do narrador na recepção da princesa de Guermantes. O narrador decide dedicar a recordação de sua vida à recriação dessas experiências em uma obra de arte; e essa obra diferirá essencialmente de todas as outras porque, em sua fundação, estala uma visão de realidade refratada através de uma perspectiva extratemporal. Muitos críticos, considerando Proust como o último e mais debilitado de uma longa linha de estetas neurastênicos, acharam meramente, nessa decisão de criar uma obra de arte, a etapa final de seu vôo para longe dos fardos da realidade. Edmund Wilson associa essa visão com a ambição de Proust de conquistar o tempo, assumindo que Proust esperava se opor ao tempo estabelecendo algo - uma obra de arte - impérvio a seu fluxo; mas isso mal faz justiça à própria convicção de Proust, expressada com especial intensidade no último volume de sua obra, de que cumpria uma missão profética. Não era a obra de arte qua obra de arte com que Proust se preocupava (seu desdém pela horda de escrevinhadores novidadeiros era desmedido), mas com uma obra de arte que pudesse permanecer como um monumento a sua conquista pessoal do tempo. Sua própria obra, contudo, podia fazer isso, não simplesmente por ser uma obra de arte, e, como todas as obras de arte, presumivelmente intemporal, mas por ser uma obra que comunicava a visão proustiana por um método a compelir o leitor a experimentar sua total significância emocional. 
O protótipo desse método, como a análise do momento revelador, ocorre durante a recepção da princesa de Guermantes. Após passar anos em um sanatório, perdendo quase que completamente o contato com o mundo elegante dos volumes anteriores, o narrador sai da reclusão para acompanhar a recepção. Sua primeira reação é de atordoamento diante das espantosas mudanças na posição social e das mudanças ainda mais espantosas no caráter e personalidade de seus antigos amigos. Na opinião de alguns críticos de inclinação para o social, a intenção de Proust nessa cena era retratar a invasão da sociedade aristocrática francesa pela alta burguesia, e a queda gradual de todos os padrões sociais e morais provocada pela Primeira Guerra Mundial. Provavelmente, esse processo é descrito incidentalmente em alguma extensão; porém, à medida que o narrador toma as grandes dores para nos contar, está longe de ser esse o significado mais importante da cena para ele. $\mathrm{O}$ que surpreende o narrador, quase que com a força de um golpe, é isso: ao tentar reconhecer os velhos amigos sob as máscaras que, da maneira como ele sente, os anos soldaram neles, ele é atirado pela primeira vez na consciência da passagem do tempo. Quando um rapaz se dirige respeitosamente ao narrador, antes que com familiaridade, como se fosse ele um cavalheiro de avançada idade, o narrador percebe repentinamente que se tornou um cavalheiro de idade avançada; mas para ele a passagem do tempo esteve imperceptível até aquele momento. Para se tornar cônscio do tempo, começa a compreender o narrador, foi necessário primeiro remover a si mesmo de seu ambiente costumeiro - ou, o que acaba por dar no mesmo, do fluxo de tempo que age naquele ambiente - e, então, arremeter de volta ao fluxo após um lapso de anos. Assim fazendo, o narrador achou-se a si mesmo presenteado com duas imagens - o mundo como ele antes o conhecera, e o mundo, transformado pelo tempo, que agora via diante de si; quando essas duas imagens são justapostas, descobre o narrador, a passagem do tempo é subitamente experimentada através de seus efeitos visíveis. O hábito, esse soporífico universal, acoberta ordinariamente a passagem do tempo daqueles 


\begin{tabular}{|l|l|l|l|l|l|l|}
\hline InterteXto & Uberaba & UFTM & $\begin{array}{l}\text { v. } 1 \\
\text { n. } 2\end{array}$ & p. 167-198 & 2008 - jul. / dez. & ISSN 1981-0601 \\
\hline
\end{tabular}

que estão acostumados com suas maneiras, pois, em qualquer momento do tempo, as mudanças são tão diminutas que se tornam imperceptíveis. "Outras pessoas", escreve Proust, "nunca param de trocar de lugar em relação a nós mesmos. Na marcha imperceptível, porém eterna, do mundo, nós as vemos como inertes em um momento de visão, curto demais para percebermos o movimento que as vai arrastando. Mas basta que selecionemos em nossa memória duas imagens tiradas delas em diferentes momentos, todavia próximos o suficiente entre si para que não tenham se alterado perceptivelmente, quero dizer - e a diferença entre eles será uma medida do deslocamento que sofreram em relação a nós". Comparando essas duas imagens em um momento do tempo, a passagem do tempo pode ser experimentada concretamente através do impacto de seus efeitos visíveis sobre a sensibilidade; não é mais meramente uma lacuna contada em números. Essa descoberta proporciona ao narrador um método que, na expressão de T. S. Eliot, é uma "objetiva correlativa" que lhe permite evocar, através do veículo de uma obra de arte, a apreensão visionária do fragmento do "tempo puro" intuído no momento revelador.

Quando o narrador descobre esse método de comunicar sua experiência do momento revelador, ele decide, como já dissemos, incorporá-lo em um romance. Mas o romance que o narrador decide escrever já foi concluído pelo leitor; e sua forma é controlada pelo método que o narrador delineou em suas páginas conclusivas. O leitor, em outras palavras, foi substituído pelo narrador, e foi colocado pelo autor, em todo o livro, na mesma posição que o narrador ocupa antes de sua própria experiência na recepção da princesa de Guermantes. Isso se dá pela apresentação descontínua do personagem - um dispositivo simples que, não obstante, é a chave para a forma da vasta estrutura de Proust. Cada leitor logo nota que Proust não segue nenhum de seus personagens durante todo o curso de seu romance: eles aparecem e reaparecem em diversos estágios de suas vidas, mas, por vezes, vão centenas de páginas entre o tempo em que são vistos pela última vez, e o tempo em que 
reaparecem; e quando eles se apresentam novamente, a passagem do tempo, invariavelmente, os modificou de alguma maneira decisiva. Em lugar de submergir o leitor no fluxo do tempo, isto é, apresentar-lhe personagens que se desenvolvem progressivamente, em uma linha contínua de desenvolvimento, Proust o confronta com diversos instantâneos dos personagens "inertes em um momento de visão" em diferentes estágios de suas vidas; e o leitor, justapondo essas imagens, experimenta os efeitos da passagem do tempo exatamente como o fizera o narrador. Conforme prometera, portanto, Proust sela seu romance indelevelmente com a forma do tempo: no entanto, encontramo-nos agora em uma posição que nos permite entender exatamente o que ele queria dizer com sua promessa.

Para experimentar a passagem do tempo, aprendeu Proust, era necessário elevar-se acima dela, e apanhar passado e presente simultaneamente em um momento do que ele chamou "tempo puro". Mas "tempo puro", obviamente, não é tempo, em absoluto - é a percepção em um momento do tempo, ou seja, espaço. Pela apresentação descontínua do personagem. Proust força o leitor a justapor imagens díspares de seus personagens espacialmente, em um momento do tempo, para que a experiência da passagem do tempo seja completamente comunicada a sua sensibilidade. Há, aqui, uma notável analogia entre o método de Proust e aquele de seus tão amados pintores impressionistas que vai profundamente além dos comentários usuais sobre o "impressionismo" do estilo de Proust. Os pintores impressionistas justapunham tons puros na tela, em vez de misturá-los na paleta, para deixar a tarefa de mesclagem das cores ao olho do espectador. Similarmente, Proust nos dá o que poder-se-ia chamar de visões puras de seus personagens - visões deles "inertes em um momento de visão" em diversas fases de suas vidas - e permite à sensibilidade do leitor fundir essas visões em uma unidade. O propósito de Proust é alcançado, portanto, apenas quando essas unidades de significação são referidas umas as outras reflexivamente em um momento do tempo. É isso, provavelmente, que Ramón Fernandez 


\begin{tabular}{|l|l|l|l|l|l|l|}
\hline InterteXto & Uberaba & UFTM & $\begin{array}{l}\text { v. } 1 \\
\text { n. } 2\end{array}$ & p. 167-198 & 2008 - jul. / dez. & ISSN 1981-0601 \\
\hline
\end{tabular}

tinha em mente quando, em uma nota de rodapé admirável para um ensaio sobre Proust, lançou a seguinte observação: "Em geral, a maneira de [Proust] fazer contato com sua 'durée' é bastante bergsoniana (vide episódio da Madeleine), mas as reações de sua inteligência sobre sua sensibilidade, que determinam a curva de sua obra, o orientariam, antes, em direção à espacialização de tempo e memória". (Itálico do texto.) Conseqüentemente, assim como em Joyce e nos poetas modernos, vemos que a forma espacial também é a armação estrutural da obra-prima labiríntica de Proust.

Consentindo que as obras já consideradas são similares em sua estrutura, que todas tem em comum a qualidade da forma espacial, surge imediatamente a pergunta: a que podemos atribuir esta surpreendente unanimidade? Para responder satisfatoriamente a essa questão, devemos primeiro ampliar os limites de nossa análise e considerar a questão mais geral da relação das formas artísticas com os climas culturais em que são criadas, essa última questão tem atraído estudantes das belas artes desde, pelo menos, a época de Herder e Winckelmann; porém, não foi senão na virada do último século que um estudo sistemático do problema se iniciou. Estimulados pela análise magistral de Hegel dos estilos de arte como objetificação sensorial de diversas atitudes em relação ao universo, um grupo de acadêmicos e críticos de arte alemães se concentrou sobre o problema da forma nas artes plásticas, elaborando diferentes categorias da forma, traçando em detalhe a mudança de um tipo de forma para outro, e tentando considerar essas mudanças em termos culturais gerais. T. E. Hulme, um dos poucos escritores de língua inglesa a se interessar seriamente por esses problemas, seguiu a direção desse grupo de acadêmicos e críticos alemães; e não podemos fazer nada melhor do que seguir seu exemplo. 
Há um escritor em particular que exerceu uma forte influência sobre Hulme e, através de Hulme e por meio de Eliot, possivelmente sobre toda a escritura crítica moderna em língua inglesa. Esse autor é Wilhelm Worringer, o autor de um livro intitulado Abstraktion und Einfühlung - traduzindo literalmente, Abstração e empatia - subtitulado uma contribuição à psicologia do estilo; e é no livro de Worringer que vamos encontrar a chave para nosso próprio problema da forma espacial ${ }^{6}$. Originalmente publicado em 1908, como tese de doutorado do autor, o livro teve inúmeras edições - um fato que, como reivindica Worringer no prefácio da terceira edição, prova que seu assunto não era meramente acadêmico, mas tocava em problemas vitais à sensibilidade moderna. Uma outra prova desse ponto, observa ainda Worringer, é que, enquanto ele e outros acadêmicos examinavam e reavaliavam estilos negligenciados, artistas criativos voltavam-se a esses estilos em busca de inspiração, encontrando neles uma forma estética melhor adaptada às necessidades de sua sensibilidade do que o naturalismo convencional do século XIX. Embora a obra de Worringer seja impecavelmente acadêmica, confinando-se estritamente ao passado e excluindo qualquer referência, exceto algumas breves, às obras contemporâneas, sua reivindicação é bastante justificada: um leitor não pode evitar ser surpreendido pela relevância das teorias de Worringer acerca dos problemas mais fundamentais da arte moderna. E sua relevância, junto com um estilo vigoroso e incisivo, que dá ao livro sua notável atmosfera de excitação e descoberta intelectual um ar que faz de sua leitura, ainda hoje, uma experiência animadora.

Em seu livro, Worringer se propõe a explicar por que, ao longo da história das artes plásticas, tem havido uma alternação contínua entre estilos naturalistas e não-naturalistas. Durante períodos de naturalismo a Idade

\footnotetext{
${ }^{6}$ Embora dois dos livros de Worringer tenham sido traduzidos para o inglês, Abstraktion und Einfühlung, infelizmente, só pode ser lido em alemão. No entanto, a segunda seção do ensaio de Hulme sobre "Arte moderna", pp. 82-91 de Especulações, é, como diz Hulme, "praticamente um resumo das visões de Worringer". Trata-se das visões apresentadas em Abstraktion und Einfühlung.
} 
Clássica da escultura e arquitetura gregas, a Renascença italiana, a arte da Europa Ocidental ao final do século XIX o artista empenha-se em representar o mundo objetivo e tridimensional da experiência ordinária e em reproduzir com dedicada acurácia os processos da natureza orgânica, na qual está incluído o homem. Por outro lado, durante períodos de não-naturalismo a arte dos povos primitivos, a escultura monumental egípcia, a arte oriental, a arte bizantina, a escultura gótica, a arte do século $X X-0$ artista abandona o mundo tridimensional e retorna ao plano, reduz a natureza orgânica, inclusive o homem, a formas geométricas lineares, e freqüentemente abandona o mundo orgânico completamente por um outro de linhas, formas e cores puras. Embora, obviamente, existam vastas diferenças entre os produtos artísticos dos diversos períodos aglomerados sob essas duas categorias, as similaridades básicas entre as obras de uma categoria, e sua oposição básica, tomadas como um grupo, a todas as obras da outra categoria, não são menos notáveis e instrutivas. Temos aqui, de acordo com Worringer, uma polaridade fundamental entre dois métodos distintos de criação nas artes plásticas; e nenhum deles pode ser estabelecido como norma à qual o outro deve aderir.

Da Renascença aos fins do século XIX, contudo, era costumeiro aceitar o naturalismo, entendido nesse sentido amplo, como o padrão para as artes plásticas. O não-naturalismo era visto como uma aberração bárbara causada por incapacidade técnica: era inconcebível que os artistas pudessem ter violado os cânones do naturalismo se não tivessem sido forçados a tanto por um baixo nível de desenvolvimento cultural. Franz Wickhoff, um famoso historiador da arte austríaco da velha escola, chamou de arte não-naturalista "o encantador balbuciar das crianças"; e essa opinião, embora tivesse perdido todo seu poder de conviç̧ão entre os artistas, provavelmente acharia alguma aceitação entre o público educado mesmo nestes dias atuais. Para combater essa elevação hostil do naturalismo como padrão estético eterno, Worringer faz uso do conceito de Kunstwollen, vontade-para-arte, originalmente empregado por outro famoso acadêmico austríaco, Alois Riegl. O impulso de criação nas 
artes plásticas, acreditava Riegl, não era primariamente uma urgência em imitar objetos naturais; pois, fosse isso verdade, o valor estético seria idêntico à habilidade na reprodução naturalista, e as melhores obras de arte seriam aquelas que mais habilidosamente duplicassem as aparências do mundo natural, em vez disso, Riegl postulava o que ele chamava de vontade-para-arte absoluta, ou, ainda melhor, vontade-para-forma; essa vontade-para-forma absoluta é o elemento comum a toda atividade nas artes plásticas, mas não pode ser identificada em nenhum estilo em particular. Todos os estilos são, para dizer a verdade, modificações dessa vontade-para-forma absoluta na medida em que encontram expressão de maneiras diversas em todo o curso da história. A importância desse conceito, aponta Worringer, é que ele transferiu o centro de gravidade no estudo dos estilos de uma causação puramente mecânica - o estado do conhecimento técnico artístico no momento em que o estilo floresceu - para uma causa baseada no emprego proposital da vontadepara-forma. "As peculiaridades de estilo nas eras passadas", escreve Worringer, "podem ser investigadas, não em questão de deficiência no conhecimento, mas em vontades-para-arte diversamente direcionadas". Desse ponto de vista, é impossível olhar o não-naturalismo como uma tentativa grotescamente malsucedida de reproduzir as aparências naturais: ele não tem interesse em tal reprodução, e não pode ser julgado como se tentasse competir com o naturalismo em seus próprios termos. Ambos os tipos de arte, criados para satisfazer diferentes necessidades espirituais, só poderão ser compreendidos se examinarmos os climas de sentimentos que levaram à predominância de uma ou de outra forma em tempos diferentes.

Uma vez aceita essa conclusão, está-se a um pequeno passo do cerne do livro de Worringer - sua discussão das condições espirituais que têm impelido a vontade para-arte a mover ou na direção do naturalismo ou na direção do não-naturalismo. Quando o naturalismo é o estilo de arte reinante, de acordo com Worringer, temos que ele é criado por culturas que alcançaram um equilíbrio com o ambiente natural de que fazem parte. Como os gregos do 
período clássico, elas se sentem parte da natureza orgânica, ou, como o homem moderno da Renascença aos fins do século XIX, estão convencidas de sua capacidade de dominar o mundo natural. Em todo caso, o mundo orgânico da natureza não guarda terrores para elas: elas têm o que Worringer chama de Vertraulichkeitsverhältnis - uma relação de confiança e intimidade com o universo; e o resultado, na arte, é um naturalismo que se deleita em reproduzir as formas e aparências do mundo orgânico objetivo e tridimensional. Acompanhando Riegl, entretanto, Worringer nos adverte a não confundir esse deleite pelo orgânico exibido pelo naturalismo com um mero impulso à imitação. Embora a imitação das formas e objetos naturais seja um subproduto do naturalismo, o que apreciamos não é a imitação per se, mas nossa sensação exaltada de participação ativa no orgânico: e é essa sensação que, demandando satisfação, vira a vontade-para-arte na direção do naturalismo quando o homem e o universo estão em relação harmoniosa.

Por outro lado, quando a relação entre homem e universo é de desarmonia e desequilíbrio, temos que aqueles estilos abstratos nãonaturalistas são sempre produzidos. Para os povos primitivos, o mundo exterior é um caos incompreensível, uma confusão absolutamente sem sentido de ocorrências e sensações. E claramente, os povos nesse nível de desenvolvimento cultural não obteriam nenhum prazer em uma apresentação objetiva do orgânico: o mundo de sua experiência ordinária é um mundo de medo, e a representação desse mundo na arte meramente intensificaria seu terror. Sua vontade-para-arte, em lugar de voltar-se para o naturalismo, vai na direção oposta: ela reduz as aparências do mundo natural a formas geométricas lineares - formas que têm a estabilidade, a harmonia e a sensação de ordem que o homem primitivo não consegue encontrar no fluxo dos fenômenos à medida que, para citar Hart Crane, eles "submergem no silêncio". Os estilos não-naturalistas também são produzidos, em um nível mais alto de desenvolvimento cultural, em períodos que, como o bizantino e o gótico, são dominados por uma religião que rejeita completamente o mundo natural, 
por considerá-lo o reino do mal e da imperfeição. Em lugar de representar as aparências naturais em toda a sua pujante vitalidade, a vontade-para-arte se volta para sua espiritualização, para a eliminação da massa e da corporeidade, para uma aproximação da eterna e etérea tranqüilidade da existência em outros mundos. Em ambos os casos - o primitivo e o transcendental - a vontade-para-arte, em conformidade com o clima de sentimentos que prevaleça, diverge do naturalismo para criar formas estéticas que satisfaçam as necessidades espirituais de seus criadores; e, em ambos os casos, essas formas se caracterizam por uma ênfase em padrões geométricos lineares, em uma eliminação dos formatos objetivos tridimensionais e do espaço objetivo tridimensional, em uma dominação do plano em todos os tipos de arte plástica ${ }^{7}$.

Não e difícil aplicar as observações de Worringer aos desenvolvimentos modernos nas artes plásticas. Em uma época como o presente, um tempo em que, como nos disse o psicólogo Erich Fromm, o homem está tentando escapar da liberdade por já não se sentir capaz de lidar com as complexidades atordoantes da existência megalopolitana, não deve ser de surpreender que os artistas - sempre os barômetros mais sensíveis da mudança cultural - tenham se voltado, em busca de inspiração, aos estilos dos períodos regidos por climas de sentimentos similares; e os resultados desse processo nas artes plásticas são também óbvios demais, dispensando comentários mais detalhados. Porém, como T. H. Hulme foi um dos primeiros a perceber, podia-se esperar que a forma estética na literatura moderna passasse por uma mudança similar em resposta ao mesmo clima de sentimentos. O ensaio mais interessante de

\footnotetext{
${ }^{7}$ Para prevenir objeções, poder-se-ia apontar que nem Worringer, nem o presente autor vêem essas distinções como absolutas em nenhum outro sentido que não o teórico. Esses diferentes estilos são construções ideais, às quais a arte dos diversos períodos tem se aproximado em maior ou menor grau. Elementos de ambos os estilos podem ser encontrados em todos os períodos; diz-se que as culturas criam uma ou outra com base na predominância, e não na exclusão absoluta. Toda a segunda parte do livro de Worringer, que está fora do escopo de nossa discussão, traça o verdadeiro grau de dominância e interpenetração de ambos os estilos nas artes plásticas das culturas selecionadas.
} 
Hulme, "Romantismo e Classicismo", é uma tentativa de definir essa mudança da maneira como ela afetou a forma literária. Infelizmente, faltou a Hulme um conceito adequado de forma estética na literatura, e ele equivocadamente tentou compensar essa deficiência adotando idéias usadas pelos críticos franceses Pierre Lasserre e Charles Maurras em sua investida contra o Romantismo. Por razões políticas e literárias, esses escritores criticaram amargamente os românticos franceses em todo terreno concebível, mais ou menos como Irving Babbitt faria com o Romantismo em geral alguns anos depois; mas o que mais impressionou Hulme na obra dos críticos franceses foi sua denúncia da subjetividade romântica, da emotividade irrestrita que o Romantismo às vezes impingia como literatura. A arte não-naturalista, notou Hulme, em sua supressão do orgânico, também suprimia o subjetivo e o pessoal da maneira como o homem moderno os entendia; o estilo correspondente na literatura também seria impessoal e objetivo, ou, pelo menos, não seria "como derramar um pote de melaço sobre a mesa de jantar"; ela teria uma "seca rigidez", a rigidez do Pope e Horácio, em oposição "à pieguice que não considera que um poema é um poema a menos que ele esteja lastimando e se queixando de uma ou outra coisa". E, conclui Hulme, "eu professo que um período de verso clássico seco e rígido se aproxima”. Embora essa profecia possa parecer ter chegado notoriamente muito perto do alvo, sabemos, dos poemas do próprio Hulme, que ele pensava em algo semelhante ao Imagismo, antes que na influência tardia de Donne e os metafísicos; mas, independentemente da acurácia de sua predição, sua adoção da antítese clássico-romântico poderia apenas confundir a questão. Em vez de seguir a direção de Worringer e tentar elaborar alguma noção precisa da forma literária que pudesse ir paralela às mudanças que estavam tendo lugar na arte moderna, Hulme nos dá uma vaga descrição dessa forma literária como sendo "seca e rígida" em qualidade, pregando essa descrição adiante a um conjunto totalmente diferente de problemas, ao invocar igualmente a forma "clássica". O grande mérito de Hulme reside em estar entre os primeiros a perceber que a 
forma literária passaria por uma mudança similar às mudanças ocorridas nas artes plásticas; mas ele falhou em definir essa forma literária com o mínimo de exatidão. Para tanto, devemos voltar a Worringer e compreender onde a feliz, mas fragmentária, intuição de Hulme cessou.

Porque a literatura é uma arte do tempo, Hulme poderia ter feito de seu ponto de partida, como faremos nós, a discussão de Worringer sobre o desaparecimento da profundidade na arte não-naturalista. As razões gerais para esse desenvolvimento já foram explicadas; mas Worringer analisa esse ponto com grande particularidade e, assim fazendo, lança uma observação de primeira importância para o entendimento da forma espacial na literatura moderna, "Espaço preenchido com luz atmosférica", escreve Worringer, "que aglutina os objetos e abole suas autocontinências individuais, confere um valor intemporal (Zeitlichkeitswert) às coisas, desenhando-as no carrossel cósmico das aparências". Apresentar os objetos em profundidade thes dá um valor temporal, ou talvez devamos dizer que acentua seu valor temporal, por conectá-las com o mundo real no qual ocorrem os eventos; e uma vez que o tempo é a própria condição daquele fluxo e mudança de que, como vimos, o homem tenta escapar quando se encontra em uma condição de desequilíbrio com a natureza, os estilos não-naturalistas esquivam-se da dimensão de profundidade e preferem o plano. Pois quando a profundidade desaparece e os objetos são apresentados em um único plano, sua apreensão simultânea como parte de uma unidade intemporal é, obviamente, facilitada, embora, para retornarmos a Lessing, as artes plásticas sejam absolutamente espaciais quando comparadas à literatura, vemos agora que ambas foram mais ou menos espaciais no curso de sua evolução interna, dependendo da extensão na qual a representação da tridimensionalidade era favorecida ou evitada. Isso significa, paradoxalmente, que as artes plásticas foram mais espaciais quando não representaram a dimensão da profundidade, e menos espaciais quando o 


\begin{tabular}{|l|l|l|l|l|l|l|}
\hline InterteXto & Uberaba & UFTM & $\begin{array}{l}\text { v. } 1 \\
\text { n. } 2\end{array}$ & p. 167-198 & 2008 - jul. / dez. & ISSN 1981-0601 \\
\hline
\end{tabular}

fizeram, já que um grau maior de valor temporal sempre acompanha a apresentação da tridimensionalidade ${ }^{8}$.

Em um estilo não-naturalista, então, a espacialidade inerente das artes plásticas é acentuada pelo esforço em remover todos os traços de valor temporal; e, uma vez que a arte moderna é não-naturalista, podemos dizer que ela está se movendo na direção de uma espacialidade cada vez maior. A significância da forma espacial na literatura moderna se torna clara agora: é o complemento exato na literatura, no plano da forma estética, aos desenvolvimentos que tiveram lugar nas artes plásticas. A forma espacial é o desenvolvimento literário que Hulme procurava, mas que não sabia como encontrar. Em ambos os veículos artísticos, um naturalmente espacial e o outro naturalmente temporal, a evolução da forma estética no século $X X$ tem sido absolutamente idêntica: ambos têm agido no sentido de vencer, na medida do possível, os elementos temporais envolvidos em sua percepção; e a razão para essa identidade é que ambos encontram-se enraizados no mesmo clima espiritual e emocional - um clima que, na medida em que afeta a sensibilidade de todo artista, deve-se também afetar as formas que eles criam em cada veículo. Em um plano puramente formal, portanto, ao demonstrarmos a completa congruência da forma estética na arte moderna com a forma na literatura moderna, nós desnudamos o que Worringer chamava de raízes "psicológicas" da forma espacial na literatura moderna. Mas, para uma

\footnotetext{
${ }^{8}$ Dagobert Frey, cujo livro Gotik um Renaissance já mencionamos, toma as categorias de espaço e tempo de Lessing e demonstra em detalhe que, do ponto de vista da percepção, as artes plásticas podem ser mais ou menos espaciais, e a literatura - para não mencionar a música - mais ou menos temporal. Frey, todavia, chama temporal a arte planimétrica nãonaturalista da Idade Média porque, para entender o significado dos símbolos comprimidos no plano-figura, o olho deve ir de um a outro no tempo e lê-los como se fossem letras de uma palavra ou partes de uma sentença.

Apesar de isso ser inquestionavelmente verdadeiro, resta o fato de que, ao lado da questão de conteúdo, a arte planimétrica da Idade Média criou formas geométricas no plano do qual foi removido todo traço de valor temporal. Eventos da vida de Cristo, por exemplo, embora possam ter ocorrido em tempos diferentes, são justapostos no mesmo plano-figura e apreendidas simultaneamente como parte de um padrão visual estilizado. Por essa razão, não podemos aceitar a terminologia de Frey como adequada para descrever a qualidade de percepção mais importante da arte medieval.
} 
verdadeira psicologia do estilo, como Worringer nos adverte nas observações citadas no início desta seção, o "valor formal" deve ser demonstrado "como uma expressão precisa do valor interno, de tal maneira que a dualidade de forma e conteúdo deixe de existir". Que elementos podem ser descobertos no conteúdo das obras que discutimos para resolver essa dualidade?

No caso de Proust, já respondemos a essa questão, mostrando que seu uso da forma espacial adveio de uma tentativa de comunicar a qualidade extratemporal de seus momentos reveladores. Ernst Robert Curtius, na conclusão de seu penetrante estudo de Proust, chama a este platonista; e esse termo se revelara bastante acurado se acharmos que Curtius quer dizer que, como Platão, Proust encontrou seu valor último em uma existência que se livrou de toda submissão ao fluxo do temporal. Proust, geralmente não se percebe, era um aluno ardente de filosofia, bem como esteta neurastênico; tinha inteira consciência das implicações filosóficas de suas próprias produções literárias. Ao conceitualizar essas implicações para nós em sua análise dos momentos reveladores, o próprio Proust explicou ao leitor a unidade entre forma e conteúdo em sua obra-prima.

Com nossos outros escritores, contudo, o problema é um bocado mais complexo. Onde Proust se preocupava com uma revelação individual, restrita, em sua obra, à esfera da experiência pessoal do narrador, os outros escritores se moviam, todos, para além do pessoal, em direção aos âmbitos mais largos da história: tudo tratava, de uma maneira ou de outra, do embate das perspectivas históricas, induzido pela identificação das figuras e eventos contemporâneos com protótipos históricos variados. Isso fica evidente nos "Cantos", em "A Terra Devastada" e em Ulisses, pois a principal fonte de significação em todos os três é a sensação de irônica dissimilaridade e, ainda, de profunda continuidade humana entre os protagonistas modernos e seus modelos há tempos falecidos. Um efeito similar de palimpsesto acha-se em $O$ Bosque da Noite, em que o Dr. O'Connor está continuamente desenhando imagens e metáforas em sua "memória pré-histórica", costurando o passado 
com o presente e identificando os dois. Allen Tate, falando dos "Cantos", escreve que "as vigorosas justaposições dos mundos antigo, renascentista e moderno" de Ezra Pound "reduzem todos os três elementos a uma miscelânea anti-histórica, intemporal e sem origem"; e isso é chamado "a qualidade peculiarmente moderna do Sr. Pound". Mas é, igualmente, a qualidade peculiarmente moderna de todas as obras que temos diante de nós - todas elas conservam uma justaposição contínua entre aspectos do passado e do presente, de tal modo que ambas são fundidas em uma visão abrangente; e tanto Tirésias quanto o Dr. O'Connor - as figuras centrais das obras em que aparecem - são o foco de consciência nessas obras precisamente porque transcendem os limites históricos e abarcam todas as épocas. (Leopold Bloom, obviamente, faz o mesmo; mas Joyce, mantendo as tradições do naturalismo, faz de Bloom o portador inconsciente de sua própria imortalidade.) Através dessa justaposição de passado e presente, como percebeu Allen Tale, a história se torna anti-histórica: já não é mais vista como uma progressão objetiva e causal no tempo, com diferenças distintamente marcadas entre cada período, mas é sentida como um continuum em que as distinções entre passado e presente estão obliteradas. Assim como a dimensão de profundidade foi se esvaecendo das artes plásticas, ela também foi se esvaecendo da história à medida que formava o conteúdo dessas obras: passado e presente são vistos espacialmente, encerrados em uma unidade intemporal que, embora possa acentuar diferenças de superfície, elimina qualquer sentimento de seqüência histórica por meio do ato mesmo da justaposição. A imaginação histórica objetiva, da qual o homem moderno tanto se orgulhava e a qual cultivou tão cuidadosamente desde a Renascença, é transformada, nesses escritores, na imaginação mítica para a qual o tempo histórico não existe - a imaginação que vê as ações e os eventos de uma época em particular meramente como novo corpo dado a protótipos eternos. Esses protótipos são criados transmutando-se o mundo temporal da história no mundo intemporal do mito. $\mathrm{E}$ 
\begin{tabular}{|l|l|} 
v. 1 & p. 167-198 \\
\hline
\end{tabular}

2008 - jul. / dez.

ISSN 1981-0601

é esse mundo intemporal do mito, formando o conteúdo comum da literatura moderna, que encontra sua expressão estética apropriada na forma espacial. 